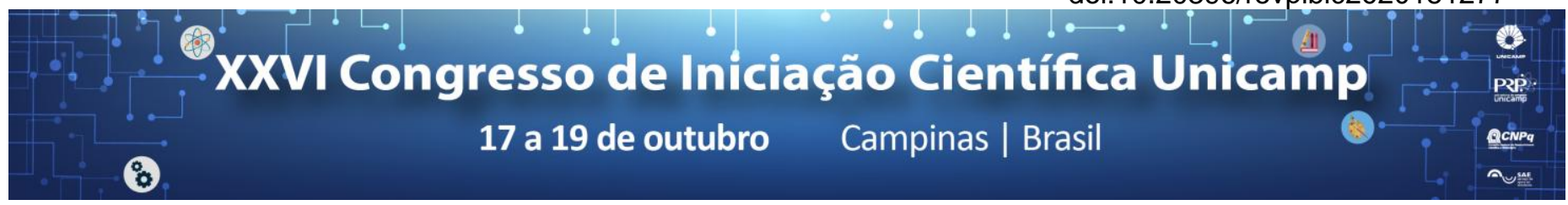

\title{
Atuação do enfermeiro diante das demandas clínicas de pacientes psiquiátricos
}

\author{
Talita R. Nicacio*, Ana Paula Rigon F. Garcia, Vanessa P. Toledo.
}

\section{Resumo}

Objetivo: conhecer como os enfermeiros de saúde mental cuidam de pacientes psiquiátricos com comorbidades biológicas. Método: estudo qualitativo apoiado no materialismo histórico e dialético. Foram realizadas entrevistas com nove enfermeiros utilizando roteiro semi-estruturado. Resultados: a atuação dos enfermeiros é marcada pela dialética entre saber e não saber, movimento que revelou duas categorias: clínica da enfermagem psiquiátrica e alienação e subordinação do enfermeiro no processo de cuidar. Considerações finais: o desenvolvimento da clínica da enfermagem, pautada na relação terapêutica, favorece o cuidado integral ao paciente, enquanto a alienação/subordinação afasta o enfermeiro do cuidado e gera prejuízos na assistência.

Palavras-chave: Enfermagem psiquiátrica, Integralidade em saúde, Comorbidade.

\section{Introdução}

Indivíduos em sofrimento psíquico têm duas a três vezes mais risco de morte e redução da expectativa de vida de 20 anos quando comparados com a população geral; entre as causas mais comuns de morte estão os problemas biológicos ${ }^{1}$. A partir da Reforma Psiquiátrica, os manicômios foram substituídos por equipamentos inseridos na comunidade, como os Centros de Atenção Psicossocial, permitindo assistir o paciente em seu meio social e não fora dele ${ }^{2}$. Nesse sentido, foi adotado o modelo de atenção psicossocial que exige do enfermeiro maior percepção das necessidades do paciente, de modo que a clínica se desenvolva com ações voltadas para o sofrimento psíquico do sujeito sem, contudo, abandonar as questões biológicas ${ }^{3}$. Objetivo: conhecer como os enfermeiros de saúde mental cuidam de pacientes psiquiátricos com comorbidades biológicas.

\section{Resultados e Discussão}

Foram entrevistados nove enfermeiros que trabalham em Centros de Atenção Psicossocial. Com base nas informações que foram relatadas nas entrevistas, os dados foram organizados em duas categorias organizadas a partir da dialética que representou 0 movimento da contradição entre saber e não saber que foram compreendidos dos discursos e estão apresentados pela clínica da enfermagem psiquiátrica e pela alienação e subordinação do enfermeiro no processo de cuidar do paciente psiquiátrico (Tabela 1).

Os enfermeiros de saúde mental estão inseridos em um contexto marcado por um movimento antagônico que, ora revela uma realidade de alienação, ora apresenta possibilidades de cuidar. Por um lado, há enfermeiros que restringem a sua atuação à medida que se afastam do lugar de quem cuida e alienam-se ao saber e ao fazer do outro. Em contrapartida, há enfermeiros que, apropriando-se do saber da enfermagem, enxergam possibilidades de cuidar a partir da relação terapêutica e dos momentos em que ocorre 0 encontro com 0 paciente.

\section{Conclusões}

O conhecimento do movimento dialético do enfermeiro se caracterizou como uma contribuição deste estudo para a enfermagem, pois tal movimento pode acarretar prejuízos na assistência ao paciente psiquiátrico com comorbidade biológica porque estando o profissional distante do cuidado, as necessidades do paciente só são vistas em situações de crise e agudização.

O desenvolvimento da clínica da enfermagem psiquiátrica foi apreendido como uma possibilidade de romper com o contexto da alienação e, assim, melhorar a assistência e favorecer a atuação do enfermeiro em ações de prevenção de agravos e promoção da saúde.

Tabela 1. Relação entre saber e não saber.

\begin{tabular}{|c|c|}
\hline $\begin{array}{l}\text { Categoria 1- Clínica da } \\
\text { enfermagem psiquiátrica } \\
\text { (saber) }\end{array}$ & $\begin{array}{lr}\text { Categoria 2- } & \text { Alienação e } \\
\text { subordinação } & \text { do } \\
\text { enfermeiro no processo } \\
\text { de cuidar do paciente } \\
\text { psiquiátrico } & \text { com } \\
\text { comorbidade } & \text { biológica } \\
\text { (não saber) } & \end{array}$ \\
\hline $\begin{array}{l}\text { - Processo de cuidar com } \\
\text { foco no sujeito e não na } \\
\text { psicopatologia; } \\
\text { - Abordagem no "caso a } \\
\text { caso"; } \\
\text { - Condutas terapêuticas. }\end{array}$ & $\begin{array}{l}\text { - Saber biomédico; } \\
\text { - Alienação pelo saber do } \\
\text { outro; } \\
\text { - Cumpre a prescrição } \\
\text { médica. }\end{array}$ \\
\hline $\begin{array}{l}\text { - Relação enfermeiro- } \\
\text { paciente; } \\
\text { - Encontro, permanência e } \\
\text { vínculo; } \\
\text { - Identificação de alterações } \\
\text { biológicas. }\end{array}$ & $\begin{array}{l}\text { - Dificuldade em determinar } \\
\text { seu lugar; } \\
\text { - Assume tarefas da equipe } \\
\text { multiprofissional. }\end{array}$ \\
\hline $\begin{array}{l}\text { - Saber reconhecer os } \\
\text { prejuízos do olhar } \\
\text { fragmentado sobre o sujeito } \\
\text { que se reflete nos serviços } \\
\text { da rede. }\end{array}$ & $\begin{array}{l}\text { - Alienação e resposta do } \\
\text { enfermeiro ao centro de } \\
\text { saúde e não determina qual } \\
\text { é o seu trabalho. }\end{array}$ \\
\hline
\end{tabular}

\section{Agradecimentos}

Ao CNPq por ter contribuído com bolsa de iniciação científica. Nota: Trabalho aprovado para publicação na Revista Brasileira de Enfermagem; vol. 71(supl. 5), 2018.

\footnotetext{
${ }^{1}$ Happell, B.; et al. Should we or shoudn't we? Mental health nurses' views on physical health care of mental health consumers. Int J Mental Health Nurs, v. 21, n. 3, p. 202-210. 2012

${ }^{2}$ Campos, R. O.; Baccari, I. P. A intersubjetividade no cuidado à Saúde Mental narrativas de técnicos e auxiliares de enfermagem de um Centro de Atenção

Psicossocial. Ciência e Saúde Coletiva, v. 16, n. 4, p. 2051-2058, abr. 2011.

${ }^{3}$ Silveira, L. C.; et al. A clínica de enfermagem em saúde mental. Revista Baiana de Enfermagem, v. 25, n. 2, p. 107-120, maio-ago. 2011.
} 